\title{
Espiritualidad de raíz latinoamericana y cultura del encuentro*
}

\author{
Patricio Merino Beas ${ }^{a}$ \\ Universidad Católica de la Santísima Concepción, Chile \\ http://orcid.org/0000-0001-5141-1887
}

RECIBIDO: 04-04-20. APROBADO: 30-06-20

RESUMEN: El presente trabajo pretende mostrar la relación entre la espiritualidad de raíz latinoamericana, que desarrollan los principales autores teológicos, con la categoría de cultura del encuentro propiciada por el papa Francisco. Específicamente quisiera desarrollar la hipótesis de que hay una coincidencia entre la categoría cultura del encuentro con las raíces teológicoespirituales más características y reconocidas de la teología latinoamericana. Esta ha conducido -con su énfasis en el misterio de la encarnación y el Reinado de Dios- a un proceso que la llevó a descubrir no solo la dignidad de los excluidos, la opción preferencial por los pobres como garantía de la apertura universal del ofrecimiento salvífico, sino también una comprensión de los otros que permite comprenderlos como prójimos. Tales características contribuyen al trabajo de los cristianos con otros ciudadanos en la construcción del bien común, la paz, la integración y la justicia, aspectos que constituyen algunos de los fines de la cultura del encuentro. Para ello, sistematizo los aportes de Gustavo Gutiérrez, Segundo Galilea, Jon Sobrino, Leonardo Boff, José María Vigíl e Ignacio Ellacuría tras acudir a sus textos más característicos, en los que explican el fundamento bíblico de sus análisis: lo bíblico. Estos autores desarrollaron una base teológica-espiritual que evidenció un binomio entre contemplación y compromiso, posibilitando el reconocimiento del Otro (movimiento de Dios en su Hijo encarnado y el envío del Espíritu) y de los otros (movimiento hacia los diversos rostros latinoamericanos) en su realidad cultural concreta. Este proceso sustentó su comprensión del otro/diverso como prójimo, y posibilitó que el otro/diverso no se transforme en adversario, ni en extraño, sino en interlocutor válido. De este modo, se desarrolló en la reflexión teológico-pastoral de América Latina un talante espiritual que permite a los discípulos no solo el diálogo, sino salir al encuentro del otro comprendido como prójimo.

Palabras Clave: Teología latinoamericana; teología de la liberación; espiritualidad; cultura del encuentro; opción por los pobres; autores latinoamericanos; contemplación y compromiso; papa francisco; diálogo; diversidad.

CÓMO CITAR:

Merino Beas, Patricio. "Espiritualidad de raíz latinoamericana y cultura del encuentro". Theologica Xaveriana vol. 72 (2022): 1-22. https://doi.org/10.11144/javeriana.tx72.erlce

*Artículo de investigación. Es parte del proyecto Direg 07/2020 de la Vicerrectoría de Investigación y Postgrado de la Universidad Católica de la Santísima Concepción.

a Autor de correspondencia. Correo electrónico: pmerino@ucsc.cl/ 


\section{Latin American Rooted Spirituality and the Culture of Encounter}

AвSTRACT: The present work seeks to illustrate the relationship that exists between the spirituality of Latin American origin, developed by the foremost theological authors, with the category of culture of encounter promoted by Pope Francis. Specifically, I would like to develop the hypothesis that there is a coincidence between the category "culture of encounter" with the most characteristic and recognized theological-spiritual roots of Latin American theology. By means of its emphasis on the mystery of the incarnation and the reign of God, a process that led her to discover not only the dignity of the excluded, and the preferential option for the poor as a guarantee of the universal offer of salvation, but also a certain understanding of others that allows them to appreciate themselves as neighbors is achieved. Characteristics that contribute to the task of Christians with other citizens in the construction of the common good, peace, integration and justice-facets that constitute some of the elements of the culture of encounter.

To this end, I systematize the contributions of Gustavo Gutiérrez, Segundo Galilee, Jon Sobrino, Leonardo Boff, José María Vigíl and Ignacio Ellacuría, based on their most characteristic texts where they explain the spiritual foundation of their analyses, which are indeed biblical. These authors developed a theological-spiritual foundation that demonstrated a relationship between contemplation and commitment, enabling the recognition of the Other (movement of God in his Incarnate Son and the sending of the Spirit) and of the others (movement towards the various Latin American presences) in their concrete cultural reality. This process supported their understanding of the other/different as neighbor. Enabling the other/diverse to not be shifted into adversary, or stranger, but understood rather as a valid interlocutor. In this way, there developed in the theological-pastoral reflection of Latin America a spiritual underpinning that allows the disciples not only to enter into dialogue, but also to go out to meet the other who is seen as neighbor.

Key Words: Latin American theology; Liberation Theology; Spirituality; Culture of the Encounter; Option for the Poor; Latin American Authors; Contemplation and Commitment; Pope Francis; Dialogue; Diversity.

\section{Planteamiento del tema}

El papa Francisco invita con insistencia a los cristianos para que sean discípulos constructores de una cultura del encuentro, categoría que propuso desde antes de asumir el ministerio petrino ${ }^{1}$ y es tema de estudio en la actualidad ${ }^{2}$. Esta categoría tiene una riqueza susceptible de ser abordada desde distintas perspectivas. Julio Martínez plantea que una de ellas es la raíz espiritual de la categoría "cultura del encuentro". Al respecto, ha escrito lo siguiente:

...muchos motivos espirituales concurren a inspirarla, pero creo que tiene enorme importancia la contemplación de la Encarnación de los Ejercicios

\footnotetext{
${ }^{1}$ Véase la obra de Fares, El olor del pastor. El ministerio pastoral en la visión del papa Francisco.

${ }^{2}$ Awi, "El papa Francisco y la cultura del encuentro", 721-750; véase a Martínez, La cultura del encuentro.

Desafio e interpelación para Europa. Ambos textos cuentan con amplia bibliografía sobre el tema.
} 
Espirituales [...] en esa contemplación hay espiritualidad trinitaria, cristológica y de decir sí a la voluntad de Dios sobre la existencia concreta vivida con alegría. ${ }^{3}$

Martínez muestra también que otra clave para la comprensión de la cultura del encuentro es la categoría de "projimidad": "La categoría clave es projimidad. Encuentro, conversión, comunión y solidaridad son categorías que expresan la projimidad [...] que abre camino a la esperanza". ${ }^{4}$

En ese orden de ideas podemos preguntarnos por los antecedentes teológicoespirituales que el papa Francisco puede tener en su propuesta de construir una cultura del encuentro. Ciertamente, sería adecuado pensarlas en el contexto de las posibles influencias de su pensamiento en general. Hasta donde he podido abarcar en mi investigación, al menos, dos serían las grandes fuentes teológico-espirituales más estudiadas que sirven como base para situar el pensamiento del papa Francisco. Una es su identidad jesuita y, por tanto, la espiritualidad que de ella mana'; y la otra, muy importante, la teología del pueblo ${ }^{6}$, al destacar la figura y pensamiento de Lucio Gera ${ }^{7}$ (sobre todo, en la relación entre las categorías de cultura-nación-pueblo-evangelización).

No obstante, quisiera plantear en este artículo que si situamos al papa Francisco en el horizonte latinoamericano, podríamos pensar en una perspectiva teológico espiritual y pastoral más amplia. Un horizonte que lo une o relaciona también con el resto de las vertientes teológico-pastorales que ha acentuado el pensamiento teológico-pastoral latinoamericano. Por ejemplo, si tomamos la influencia que ha tenido en Francisco la teología del pueblo, decantadas en el pensamiento teológico argentino, hace ya varias décadas Juan Carlos Scannone nos advirtió que dicha teología del pueblo se relaciona, con sus especificaciones propias, con las otras que se daban en América Latina y que se enmarcan entre las diversas teologías de la liberación ${ }^{8}$.

\footnotetext{
${ }^{3}$ Martínez, La cultura del encuentro. Desafio e interpretación para Europa, 54-55.

${ }^{4}$ Ibíd., 18.

${ }^{5}$ Así lo señala Martínez, La cultura del encuentro. Desafio e interpelación para Europa, 54; véase también a Bresciani y otros, El papa Francisco y la espiritualidad; y a Bingemer, "La consolación y el bien mayor. Sobre la espiritualidad y la inteligencia de la fe del papa Francisco", 532-550. También podríamos mencionar a autores como Romano Guardini y Von Balthasar.
}

${ }^{6} \mathrm{Al}$ respecto véase a Scannone, La teología del pueblo. Raíces teológicas del papa Francisco; a Lucciani, El papa Francisco y la teología del pueblo; y a Albado, "La teología del pueblo: su contexto latinoamericano y su influencia en el papa Francisco", 31-57.

${ }^{7}$ Véase a Ferrara y Galli (eds.). Presente y futuro de la teología en Argentina. Homenaje a Lucio Gera.

${ }^{8}$ Véase a Scannone, "La teología de la liberación. Caracterización, corrientes, etapas", 3-40. Así lo recoge y asevera también Albado, "La teología del pueblo: su contexto latinoamericano y su influencia en el papa Francisco". 
Por otro lado, se podría analizar también cómo en el ejercicio del ministerio episcopal, el entonces obispo Bergoglio se relaciona con el conjunto de las opciones del episcopado latinoamericano. Al respecto es suficientemente conocido su rol en la Conferencia y "Documento final de Aparecida”, así como la influencia de aquella en la encíclica Evangelii gaudium ${ }^{9}$.

Por estos motivos propongo como hipótesis la existencia de importantes coincidencias entre los planteamientos de la categoría de cultura del encuentro del papa Francisco y otras raíces teológico-espirituales características y reconocidas de la teología latinoamericana que ofrecen una perspectiva más amplia a la que pueda tener, reductivamente, la teología del pueblo de Dios. Con esto, solo pretendo mostrar que las propuestas de teólogos que en América Latina han trabajado y contribuido a decantar una espiritualidad de raíz latinoamericana pueden enriquecer, si cabe, la comprensión de la propuesta de una cultura del encuentro.

La espiritualidad latinoamericana emergió de los planteamientos de muchos reconocidos teólogos latinoamericanos, quienes coincidieron en visibilizar algunas categorías teológico-espirituales emanadas del énfasis en el misterio de la encarnación y el Reinado de Dios. Esto les llevó a destacar, desde una opción preferencial por los pobres y la dignidad de toda persona, el ofrecimiento universal de la salvación. Tales categorías contribuyeron y contribuyen, de igual manera, al trabajo de los cristianos con otros ciudadanos para la construcción del bien común, la paz, la integración y la justicia, aspectos que forman parte de los fines de la cultura del encuentro y de entender al otro como prójimo.

\section{Espiritualidad latinoamericana para una cultura del encuentro}

El "Documento de Aparecida" y la exhortación Evangelii gaudium nos han hecho, últimamente, más conscientes de la íntima unión que hay entre teología, pastoral y espiritualidad, entre discipulado misionero y construcción del bien común. Esto nos lleva a proponer que, en América Latina, la fisonomía propia que ha tenido su teología y su pastoral tienen raíz común en una espiritualidad con acentuaciones particulares. Así las cosas, las tres se nutren mutuamente ${ }^{10}$.

9 Galli, "Francisco y Aparecida hacia el futuro".

${ }^{10}$ Azcuy, "Evangelización con Espíritu (EG 261). La unidad de la teología, la espiritualidad y la pastoral al servicio del anuncio del Evangelio", 73-93; Galli, "Lectura teológica del texto de Evangelii gaudium en el contexto del ministerio pastoral del papa Francisco", 47-88; Merino, "El aporte de Segundo Galilea a la interrelación entre espiritualidad, teología y pastoral. Clave pneumatológica”, 45-66. 
En sentido amplio, la espiritualidad cristiana es vivir según el mismo Espíritu Santo que animaba y actuaba en Jesús ${ }^{11}$, contextualizado y vivido en cada tiempo y lugar por los cristianos. Por tanto, el discipulado cristiano expresa una espiritualidad que se vive concretamente en cada cultura. Podemos aventurar que el modo de ser discípulos que se ha ido condensado en América Latina puede tener acentuaciones que permitirían hablar de un talante propio que se nutre de los aportes y discernimientos, tanto de unas teologías ejercidas desde esta patria grande, como de la vida cristiana de los diversos agentes de pastoral; así mismo, desde la reflexión, orientación y animación por parte de los obispos reunidos en sus asambleas generales del episcopado ${ }^{12} \mathrm{y}$ en las distintas conferencias episcopales (en el caso de los cristianos católicos).

Algunas de esas situaciones concretas y de conciencia reciente, todavía en discernimiento, son la pluralidad cultural, el secularismo, las ciencias de la complejidad, la diversidad religiosa y cristiana que va caracterizando nuestra sociedad. En este sentido, cobra fuerza el llamado a la construcción de lo que el papa Francisco, hijo de nuestras tierras, denomina como "cultura del encuentro" ${ }^{13}$. Esta cultura, junto con el diálogo, constituyen un verdadero método de evangelización, tal y como se desarrolló fuertemente en el magisterio del papa Pablo $\mathrm{VI}^{14}$, el cual ha influido mucho en el papa Francisco ${ }^{15}$.

La tesis consiste en que el encuentro con Jesucristo implica, a su vez, el encuentro con los demás, para generar una cultura de la cercanía y la inclusión, no de descartados ni de excluidos. Esta cultura del encuentro permite poner el énfasis en la búsqueda del bien común y de la paz. El imaginario que propone el papa Francisco es la figura del poliedro ${ }^{16}$, que permite incorporar la unidad en medio de la diversidad de formas

${ }^{11}$ Cozzi, "El exceso del Origen y la novedad del Don. Caminos recientes para decir la acción, la presencia y la identidad del Espíritu de Cristo", 51-97; Del Cura, "El Dios más humano: la espiritualidad que bebe en las fuentes del Dios Trinitario", 221-280.

12 Véase los documentos completos publicados por el Consejo Episcopal Latinoamericano, Las cinco conferencias generales del episcopado latinoamericano.

${ }^{13}$ Para profundizar en esta categoría y en la bibliografía, véase a Awi, "El papa Francisco y la cultura del encuentro", 721-750; y a Martínez, La cultura del encuentro. Desafio e interpelación para Europa.

${ }^{14}$ Pablo VI, "Carta encíclica Ecclesiam suam. El 'mandato' de la Iglesia en el mundo moderno (1964)”; Pablo VI, "Exhortación apostólica Evangelii nuntiandi al episcopado, al clero y a los fieles de toda la Iglesia acerca de la evangelización en el mundo contemporáneo (1975)".

${ }^{15}$ Véase a Galli, "Pablo VI y Francisco. La alegría de Cristo". Aquí, sin duda, han sido muy importantes los aportes de la teología del pueblo, con autores como Lucio Gera; sobre todo, por la valoración de la categoría de cultura, pueblo-nación, evangelización y religiosidad popular.

${ }^{16}$ Francisco, "Exhortación apostólica Evangelii gaudium sobre el anuncio del Evangelio en el mundo actual (2013)" 236. 
de vida y perspectivas, donde también puede caber el conflicto ${ }^{17}$. Al respecto, Francisco nos ha dicho lo siguiente:

Vivimos una cultura del desencuentro, una cultura de la fragmentación, una cultura en la que lo que no me sirve lo tiro, la cultura del descarte. Pero sobre este punto os invito a pensar -y es parte de la crisis- en los ancianos, que son la sabiduría de un pueblo, en los niños [...] ¡la cultura del descarte! Pero nosotros debemos ir al encuentro y debemos crear con nuestra fe una "cultura del encuentro", una cultura de la amistad, una cultura donde hallamos hermanos, donde podemos hablar también con quienes no piensan como nosotros, también con quienes tienen otra fe, que no tienen la misma fe. Todos tienen algo en común con nosotros: son imágenes de Dios, son hijos de Dios. Ir al encuentro con todos, sin negociar nuestra pertenencia. ${ }^{18}$

En otra parte insiste Francisco:

Alentándonos mutuamente, hemos dialogado fraternalmente. Ha sido un signo de que el encuentro y la unidad hay que buscarlos siempre, sin temer las diferencias. Así también la paz: hay que cultivarla también en las áridas tierras de las contraposiciones, porque hoy, a pesar de todo, no hay alternativa posible a la paz. La paz no vendrá gracias a las treguas sostenidas por muros y pruebas de fuerza, sino por la voluntad real de escuchar y dialogar. Nosotros nos comprometemos a caminar, orar y trabajar, e imploramos que el arte del encuentro prevalezca sobre las estrategias de confrontación, que la ostentación de los amenazantes signos de poder deje paso al poder de los signos de esperanza: hombres de buena voluntad y de diferentes credos que no tienen miedo de hablarse, de aceptar las razones de los demás y de cuidarse unos a otros. Solo así, cuidando que a nadie le falte pan y trabajo, dignidad y esperanza, los gritos de guerra se transformarán en cantos de paz. ${ }^{19}$

Para los conocedores de la tradición teológica latinoamericana, estos llamados del papa Francisco nos resultan tremendamente familiares: en primer lugar, para los estudiosos de la teología del pueblo ${ }^{20}$; pero también lo vemos en el recorrido del discernimiento teológico y pastoral de los principales autores de otras vertientes de la teología latinoamericana que nos han iluminado en este sentido.

Faustino Teixeira nos advirtió que en la acogida de la pluralidad o diversidad, tanto cultural como religiosa de América Latina, tuvo un rol central la perspectiva

\footnotetext{
${ }^{17}$ Ibíd. 226.

${ }^{18}$ Francisco, "Vigilia de Pentecostés con los movimientos eclesiales. Palabras del santo padre (18 de mayo de 2013)".

${ }^{19}$ Francisco, "Visita a Bari: Palabras del santo padre al término de la jornada (7 de julio de 2018)".

${ }^{20}$ Albado, "La teología del pueblo: su contexto latinoamericano y su influencia en el papa Francisco", 31-57 (con amplia bibliografía).
} 
espiritual de la teología y pastoral que se fue gestando en América Latina, que favoreció "la creación de un clima esencial de apertura y de acogida de la diversidad, de sensibilización a la gratuidad y disponibilidad al don siempre mayor de Dios" ${ }^{21}$. En efecto, el encuentro del Evangelio con la sapiencialidad de la cultura ${ }^{22}$ criolla y la religiosidad de los pueblos originarios latinoamericanos configuraron una identidad que diversos teólogos conceptualizaron y sistematizaron, y aportaron con ello al bien de toda la Iglesia ${ }^{23}$.

Este talante espiritual ha mostrado, poco a poco, la capacidad para salir al encuentro respetuoso del otro, valorar las alteridades, reconocerles su lugar en el plan salvífico, y establecer una relación fecunda, pero sin romper la identidad cristiana y su pretensión constitutiva en el don de la salvación. Hay, por tanto, en el discipulado cristiano latinoamericano, una base espiritual que ha propiciado la búsqueda del diálogo y ha invitado a salir al encuentro del otro, tal y como hoy pregona el papa Francisco con su invitación a contribuir a una cultura del encuentro.

¿Cómo han entendido la raíz espiritual que anima la teología latinoamericana los principales autores? ¿Qué categorías han surgido de ella? Gustavo Gutiérrez definía la espiritualidad de la siguiente manera:

... es una forma concreta, movida por el Espíritu, de vivir el Evangelio. Una manera precisa de vivir ante el Señor en solidaridad con todos los hombres, con el Señor y ante los hombres. Ella surge de una experiencia espiritual intensa, que luego es tematizada y testimoniada.

[...] Una espiritualidad significa una reordenación de los grandes ejes de la vida cristiana en función de ese presente. Lo nuevo está en la síntesis que opera, en provocar la profundización de ciertos temas, en hacer saltar a la superficie aspectos desconocidos u olvidados y, sobre todo, en la forma como todo eso es hecho vida, oración, compromiso, gesto. ${ }^{24}$

Por otra parte, Leonardo Boff recalcó que no hay praxis de liberación sin espiritualidad:

Se halla en marcha, dentro de las comunidades cristianas, un amplio y perfectamente articulado proceso de liberación que nace de la unidad entre fe y vida.

${ }^{21}$ Teixeira, "Teología del pluralismo religioso en América Latina", 22; Merino, "La diversidad religiosa como problema teológico en América Latina. Relación entre la teología de la liberación y la religiosidad popular", 245-279 (con amplia bibliografía).

${ }^{22}$ Véase a Scannone, Teología, cultura popular y discernimiento.

${ }^{23}$ Congregación de la Doctrina de la Fe, "Instrucción libertatis conscientia sobre libertad cristiana y liberación (1986)".

${ }^{24}$ Gutiérrez, Teología de la liberación. Perspectivas, 267. 
[...] Pero tanto la práctica como la teoría liberadora se apoyan en una experiencia espiritual de encuentro con el Señor en los pobres. Tras de toda práctica innovadora en la Iglesia, en la raíz de toda nueva y verdadera teología, late una experiencia religiosa típica que constituye la palabra-fuente: todo lo demás viene de esa experiencia totalizante; todo lo demás es un intento de traducción dentro de los marcos de una realidad históricamente determinada... Toda experiencia espiritual significa un encuentro con el rostro nuevo y desafiante de Dios. ${ }^{25}$

Para Jon Sobrino, la vivencia de las bienaventuranzas y la experiencia de la gratuidad de Dios son las principales fuentes para lo que él llamó "el talante espiritual” ${ }_{26}$ que informa a la espiritualidad subyacente a la teología latinoamericana, y agregó: "La teología vive, antes que nada, de una práctica y de una espiritualidad. Esa práctica no es otra cosa que el seguimiento de Jesús en nuestra historia, y esa espiritualidad, no es otra cosa que la actualidad del espíritu de Jesús" ${ }^{27}$. Esta espiritualidad busca el encuentro con Dios, pero acentúa que este encuentro se concretiza en la historia y tiene su mediación en el encuentro con los pobres y excluidos.

Pedro Casaldáliga y José María Vigíl, en su importante obra Espiritualidad de la liberación, a propósito de la pregunta de cuál es la especificidad de la espiritualidad liberadora, nos dicen que esta no es otra que el "seguimiento de Jesús"28.

Finalmente, sin lugar a duda, uno de los principales autores que desarrolló el contenido espiritual de la teología latinoamericana -sobre todo su relación con la pastoral y la teología- fue Segundo Galilea ${ }^{29}$. Sorprende cómo, en los años 80 del siglo pasado, hablaba con el mismo contenido que emplearía Aparecida dos décadas después, y el papa Francisco, posteriormente. Galilea nos decía:

Para que la espiritualidad sea la inspiración y garantía evangélica que acompañe la renovación de nuestra Iglesia, ha de recuperar lo mejor de la tradición espiritual de la Iglesia encarnándola en nuevas tareas y experiencias [...] Concretamente no hay verdadera renovación eclesial sin una transformación de las instituciones, de la calidad y orientación de las actividades, de la mística o espiritualidad.

\footnotetext{
${ }^{25}$ Boff, La fe en la periferia del mundo. El caminar de la Iglesia con los oprimidos, 209-210; véase también a Boff, Vivir en el Espiritu según el Espiritu.

${ }^{26}$ Ibíd., 153.

${ }^{27}$ Sobrino, Liberación con Espiritu. Apuntes para una nueva espiritualidad, 8.

${ }^{28}$ Casaldáliga y Vigíl, Espiritualidad de la liberación, 34.

${ }^{29}$ Para una abundante bibliografía sobre la obra de Segundo Galilea, véase el artículo de Merino, "Homenaje a una vida y obra: Segundo Galilea, discípulo misionero de Jesucristo", 539-557; y Merino, "El aporte de Segundo Galilea a la interrelación entre espiritualidad, teología y pastoral. Clave pneumatológica”, 45-66.
} 
[...] los misioneros, los evangelizadores en la frontera de la Iglesia, son los primeros en advertir la insuficiencia de las modalidades tradicionales de acción, la crítica de la pastoral comienza a partir de la experiencia de la misión en la periferia. ${ }^{30}$

Lo expuesto sobre la raíz espiritual que ha caracterizado la teología y pastoral latinoamericana muestra que esta espiritualidad se basa en la contemplación del misterio de la encarnación y, por ende, del seguimiento de Jesucristo en su quehacer histórico. ¿Cómo pueden contribuir los planteamientos de estos autores a la actual categoría de cultura del encuentro?

\section{Espiritualidad de la fraternidad para salir al encuentro del otro comprendido como prójimo}

$\mathrm{Al}$ avanzar con nuestra argumentación estamos en condiciones de proponer que el denominado binomio contemplación y compromiso marcó el talante espiritual propio del discipulado cristiano como se configuró en América Latina. Este binomio fue expuesto con diversas nomenclaturas por los autores más importantes: contemplación y compromiso ${ }^{31}$; encuentro con Dios en la historia ${ }^{32}$; liberación como encuentro de la política y de la contemplación ${ }^{33}$; los dos ojos de la teología o theologia ante et retro oculata ${ }^{34}$; encuentro con el Señor y discipulado ${ }^{35}$; espíritu liberador en la patria grande $^{36}$. La Quinta Conferencia General del Episcopado, en Aparecida, recogió esta rica tradición y habló del encuentro con Cristo y del discipulado misionero ${ }^{37}$.

La contemplación y el compromiso concentran y destacan varias categorías claves para la fe cristiana y latinoamericana que van unidas. Nos referimos a las categorías de encuentro con Cristo, seguimiento, discipulado misionero, conversión, revelación en la historia, presencia de Dios, signos de los tiempos, transformación, unión fe-vida, cultura cristiana, promoción humana, etc. Además, este binomio se

\footnotetext{
${ }^{30}$ Galilea, El camino de la espiritualidad, 17.

${ }^{31}$ Véase a Galilea, Religiosidad popular y pastoral.

32 Véase a Gutiérrez, Teología de la liberación. Perspectivas.

${ }^{33}$ Galilea, "La liberación como encuentro de la política y de la contemplación”, 313-327.

${ }^{34}$ Véase a Boff, La fe en la periferia del mundo. El caminar de la Iglesia con los oprimidos.

${ }^{35}$ Véase a Galilea, La inserción en la vida de Jesús y en la misión; y a Gutiérrez, Beber del propio pozo.

${ }^{36}$ Véase a Casaldáliga y Vigíl, Espiritualidad de la liberación.

${ }^{37}$ Consejo Episcopal Latinoamericano, Las cinco conferencias generales del episcopado latinoamericano: "Documento de Aparecida"; Brighenti, "Criterios para una lectura del Documento de Aparecida. El pretexto, el contexto y el texto", 161-180; véase a Brighenti, Para entender Aparecida. Ya antes el "Documento de Santo Domingo" (1992) había hecho lo propio.
} 
encuentra íntimamente relacionado con la categoría de Reino de Dios, tan importante en la reflexión espiritual, teológica y pastoral de América Latina ${ }^{38}$.

De todas maneras, en la gran mayoría de los autores clásicos latinoamericanos es claro que la contemplación y el compromiso implican, a su vez, dos categorías relacionales: encuentro con Jesucristo y conversión, ambas en doble movimiento íntimamente entrelazado: encuentro con Dios y con la humanidad, conversión a Dios y a los pobres-excluidos.

Con los antecedentes que hemos expuesto, pienso que la propuesta de una cultura del encuentro del papa Francisco es coincidente con la perspectiva teológico pastoral que emana de la espiritualidad latinoamericana, y ofrece un horizonte más amplio que el gran aporte a su pensamiento que ha hecho la teología del pueblo de Dios.

Asumir la categoría de encuentro implica el reconocimiento del Otro (movimiento de Dios que envía al Hijo encarnado y el envío del Espíritu) y de los otros (movimiento hacia los diversos rostros latinoamericanos) ${ }^{39}$ en su concreta realidad y entendidos como "prójimos"40. Este movimiento de compromiso, tematizado como salir al encuentro del prójimo y el compromiso de transformación, tienen un fundamento teológico-contemplativo que implica otro doble movimiento: la contemplación del otro y de los otros; este permite que el otro no se transforme en adversario, ni enemigo, ni extraño, ni sea tan solo un destinatario al que hay que ir a entregar el Evangelio integral.

Tampoco implica caer en una práctica pastoral carente de alma, en un pragmatismo sin valores, ni en una mera ética de la acción. En cambio permite comprender al otro en cuanto prójimo: como aquel en quien el Padre, por medio del Hijo encarnado y del Espíritu Santo enviado, se ha acercado, lo ha acogido y lo ha dignificado, al denominarlo privilegiado en su Reino. De aquí surgió la famosa frase: "Los pobres nos evangelizan" ${ }^{41}$.

El fundamento teológico principal de este doble movimiento de encuentro, con Dios y con los otros, entendidos como prójimos, no sería otro que el movimiento contemplado en el misterio de la encarnación del Verbo y el envío del Espíritu ${ }^{42}$ (Ga 4,4-6). En la historia humana concreta de Jesucristo, del discernimiento de

\footnotetext{
${ }^{38}$ Véase a Ellacuría, Conversión de la Iglesia al Reino de Dios. Para anunciarlo y realizarlo en la historia.

${ }^{39}$ Gutiérrez, "Praxis de liberación. Teología y anuncio", 353-374; véase a Galilea, Religiosidad popular $y$ pastoral.

${ }^{40}$ Una síntesis del recorrido latinoamericano para llegar a la idea del otro como prójimo lo encontramos en Merino, teología latinoamericana y pluralismo religioso, 62-119.

${ }^{41}$ Véase, por ejemplo, la importante obra de Galilea, ¿Los pobres nos evangelizan?

${ }^{42}$ Gutiérrez, Teología de la liberación. Perspectivas, 249.
} 
la presencia del Espíritu y de los signos de los tiempos ${ }^{43}$, se nos ha hecho visible la presencia y obra de Dios ${ }^{44}$. Estos acontecimientos marcan una presencia renovada de Dios en la historia, en las culturas ${ }^{45}$ y en la vida de cada ser humano, que viene a enriquecer el misterio de la creación.

Para los teólogos latinoamericanos que hemos mencionado, al seguir el dato bíblico, se da un encuentro con Dios en el encuentro con el otro realizado en la historia: "Si cada hombre es el templo vivo de Dios, a Dios lo encontramos en el encuentro con los hombres, en el compromiso con el devenir histórico de la humanidad" ${ }^{46}$. Este encuentro con Dios y la conversión a él queda mediado por otro movimiento: la conversión al otro. Esta significa una "transformación radical de cada uno, significa pensar, sentir y vivir como Jesús se relacionó con en el hombre despojado y alienado”7 Gustavo Gutiérrez nos explica bien esta cuestión cuando dice:

La conversión es una salida de uno mismo y una apertura a Dios y a los demás, ella implica ruptura, pero, sobre todo, significa emprender una nueva senda.

[...] El encuentro con Cristo en el pobre constituye una auténtica experiencia espiritual. Un vivir en el Espíritu, lazo de amor, entre el Padre y el Hijo, entre Dios y el hombre, entre hombre y hombre. ${ }^{48}$

Al seguir la idea de que la conversión implica el movimiento de salida de sí mismo, diversos autores la asociaron a las imágenes bíblicas de desierto, éxodo, cautiverio, etc. Por ejemplo, Segundo Galilea, nos habla del binomio "éxodo-conversión" 49 como un salir al desierto para ir al encuentro con Dios. Salida-conversión invitan también a una necesaria purificación.

La fundamentación bíblica que realizan estos teólogos es abundante en textos del Antiguo y del Nuevo Testamento; pero hay tres textos del Evangelio que de alguna manera son coincidentemente recogidos por los autores y resultan iluminadores: Ç Mt 25,31-45; Lc 10,29 y Mt 5,1-12 // Lc 6,20-23.

${ }^{43}$ Para profundizar la historia y perspectivas de esta categoría de los signos de los tiempos, véase la obra de Merino, La categoría teológica signos de los tiempos. Desde el Concilio Vaticano II al Pentecostés de Aparecida y Francisco.

${ }^{44}$ Para una visión más específica de esto y las acentuaciones de Jon Sobrino, véase el artículo de Costadoat, "Cristo liberador, mediador absoluto del Reino de Dios", 97-113.

${ }^{45}$ Esta perspectiva fue destacada por el papa Juan Pablo II, "Carta encíclica Redemptoris misio sobre la permanente validez del mandato misionero (1990)"

${ }^{46}$ Gutiérrez, Teología de la liberación. Perspectivas, 249. Las mismas ideas son desarrolladas por el autor en su obra, Hablar de Dios desde el sufrimiento del inocente.

${ }^{47}$ Gutiérrez, Teología de la liberación. Perspectivas, 268.

${ }^{48}$ Gutiérrez, "Praxis de liberación. Teología y anuncio", 363.

${ }^{49}$ Galilea, "La liberación como encuentro de la política y de la contemplación”, 321. 
La exégesis pastoral de Mt 25 permite acentuar el encuentro con Cristo a partir del encuentro con el otro (los pequeños). Por una parte, este texto promueve la fraternidad y el compromiso, la premura del hacer por sobre el saber ${ }^{50}$. Existe otro aspecto importante que la exégesis de la espiritualidad latinoamericana hace de este texto: la dimensión trascendente y gratuita de la fe. El hombre, llamado a la comunión con Dios, requiere de la fraternidad humana como mediación que se ejerce en la caridad y en la acogida del Espíritu.

El don de llamar a Dios Abbá cambia la existencia del cristiano. Esto último implica que el discipulado de los hijos inaugura también el camino de la fraternidad y la superación del individualismo y el egoísmo, Buena Noticia que queda plasmada maravillosamente en la misma celebración eucarística.

Por su parte, la acentuación latinoamericana de la exégesis de Lc 10,29-37 sigue más o menos los mismos términos; insiste en la necesidad de los gestos concretos y de que el amor implica obrar en justicia, dicho clásicamente, la fe obra por la caridad. Aquí el otro es el prójimo. Su fundamento está en Dios mismo, porque él, en Jesús, se ha hecho nuestro prójimo. Gustavo Gutiérrez la resume así: "El prójimo no es aquel que encuentro en mi camino, sino aquel a quien yo me acerco y busco activamente" ${ }^{11}$.

Esta actitud encuentra su profundo sentido teológico en el misterio de la encarnación y la historia concreta de Jesús. Dios se ha acercado al mundo y a la humanidad en Jesucristo, y con ello, los discípulos movidos por el Espíritu se identifican con esa actitud y son empoderados para hacer lo mismo. Desde esta misma raíz teológicoespiritual se introduce la opción por los pobres y excluidos, en cuanto se identifican con los despojados y los marginados a los que Jesús se acerca $^{52}$, por quienes Dios ha hecho una clara opción, a la vez que otorga una acentuación mucho más activa y comprometida al principio cristiano del amor al prójimo.

Por último, el tercer texto inspirador es el de las bienaventuranzas, con preferencia el de Lc 6, 20, ya que permitió unir la opción por los pobres con la centralidad del reino de Dios ${ }^{53}$.

De los elementos señalados ligados al binomio contemplación-compromiso o encuentro-conversión, que permitió adquirir la conciencia de comprender al otro como prójimo, se desprenden todavía tres temas que nos parecen importantes: la fraternidad cristiana, la gratuidad, y la fidelidad a lo real.

\footnotetext{
${ }^{50}$ Gutiérrez, Teología de la liberación. Perspectivas, 256.

${ }^{51}$ Ibíd., 257.

${ }^{52}$ Ibíd., 257.

${ }^{53}$ Véase, como ejemplo, el artículo de Sobrino, "Espiritualidad y liberación”.
} 
1. La espiritualidad acentuada en América Latina resalta claramente el llamado a la fraternidad. Su fundamento es el hecho de que Jesucristo es verdadero hermano nuestro: "La integración histórica de Dios en la humanidad a través de Jesús, el hijo de María, no es un mito ni una idea abstracta. Significa que el queda para siempre nuestro hermano" ${ }^{44}$. La filiación en Jesucristo nos regala la fraternidad. A partir de la identidad de Jesús como Hijo de Dios y en relación con la unidad de toda la historia de la salvación (creación-redención-consumación) se desprende la fraternidad ofrecida a todos.

De este modo, la fraternidad cristiana queda constituida como fermento y profecía de aquello a lo que todos estamos llamados. Y el modo principal de anunciar esta fraternidad y de invitar a vivirla es el servicio y el testimonio, vivido como" el grano de levadura que fermenta la masa"ss, ejercido por medio de la caridad y la justicia.

2. El segundo elemento nos habla de la gratuidad de la salvación y del discipulado cristiano. La acción de Jesucristo a favor de los marginados y excluidos es absolutamente desinteresada. "La gratuidad de Dios hace al hombre agraciado" ${ }_{56}$ y esta debería ser correspondida con el agradecimiento y la conversión. La vivencia de la gratuidad y el agradecimiento abren el camino a la universalidad de la espiritualidad liberadora, porque esta liberación-salvación está fundada en "la absoluta gratuidad del don de la comunión con Dios y desde él con todos los hombres en Jesucristo y su Espíritu" ${ }^{\text {"7 }}$.

Nuevamente, a propósito del tema de la gratuidad, se deja ver en toda su hondura el binomio contemplación-compromiso y encuentro-conversión. En efecto, la contemplación de la gratuidad de Dios y su don, que se expresan por ejemplo en la oración y meditación de su Palabra, no implican una actitud pasiva, sino vigilante y en movimiento de conversión.

3. El tercer elemento sería la acentuación de lo que Jon Sobrino llamó "fidelidad a lo real”"58, es decir, a la historia concreta de Jesús y su predicación del Reino de Dios. Sobrino, a través del análisis de la actuación de Jesús y en la búsqueda de ser fieles a ella, distingue tres actitudes espirituales básicas.

A la primera la llama honradez de lo real y -con base en Rm 1,18ss.- enfatiza la realidad de la injusticia que se vive en América Latina. De ahí que, en fidelidad a Jesucristo y a la realidad del continente, es necesaria una conversión en la que los

\footnotetext{
${ }^{54}$ Galilea, Religiosidad popular y pastoral, 199.

55 Ibíd., 202.

${ }^{56}$ Sobrino, "Espiritualidad y liberación”, 155.

${ }^{57}$ Gutiérrez, Teología de la liberación. Perspectivas, 269.

${ }^{58}$ Sobrino, Liberación con espiritu. Apuntes para una nueva espiritualidad, 23.
} 
pobres han sido nuestros principales profetas y maestros. En el relato del siervo de Yahveh y en la acción de Jesucristo crucificado, quedaría - para Sobrino- de manifiesto que incluso frente al silencio de Dios ambos mantuvieron su palabra y tuvieron una actitud firme, asumiendo fielmente la realidad.

Por último, Sobrino propone mirar la realidad y descubrir en ella su más o plus, es decir, que hay en ella una promesa y una esperanza nunca acallada. Por tanto, esperanza y amor son las formas de corresponder a lo que de más tiene la realidad: "Jesús descubrió que para que la historia dé más de sí, el sujeto tiene que dar de sí mismo y a sí mismo" 59 viviendo el mandamiento del amor.

Podemos decir que esta espiritualidad acentuada en América Latina, centrada en la contemplación y el compromiso, como también en el encuentro y la conversión, permitió evidenciar la fraternidad y la oferta universal y gratuita de la salvación. Esta situación posibilitó el encuentro con el otro, al asumirlo como prójimo.

En efecto, centrarse en la historia de Jesús, el Ungido lleno del Espíritu, como historia de la autocomunicación plena de Dios, produjo una revitalización del acontecimiento salvífico, al entenderlo como Buena Noticia que nos hace alegres discípulos y hermanos ${ }^{60}$. Además, permitió fundamentar que la opción por los pobres es evidencia concreta de la universalidad de la oferta salvífica. Sobre este último punto nos referiremos a continuación.

\section{La opción por los pobres como projimidad y universalidad}

La opción por los pobres ${ }^{61}$ es una de las características más visibles de la espiritualidad de raíz latinoamericana y concreta en nuestra historia la categoría de encuentro que rompe la exclusión. Los pobres son los primeros destinatarios del Reino de Dios y quienes dan concreción al contenido del Reino, ya que solo ellos pueden saber de lo que el Reino les libera (Lc 4,12ss.). Este hecho manifiesta que precisamente este Reino es de Dios y no se acomoda necesariamente a nuestra racionalidad, y recalca en que la mediación histórica de los pobres es parte integrante de la novedad del Evangelio y del misterio y la trascendencia de Dios mismo.

Para Ellacuría, el sentido teológico de la opción por los pobres radica en que ellos "constituyen la máxima y escandalosa presencia profética y apocalíptica del Dios

\footnotetext{
${ }^{59}$ Ibíd., 30.

${ }^{60}$ Galli, "Lectura teológica del texto de Evangelii gaudium en el contexto del ministerio pastoral del papa Francisco", 47-88; Igualmente, véase a Merino, "La otra economía: el Dios en salida como contenido y fuente de Evangelii gaudium, 109-124".

${ }^{61}$ Lois, Teología de la liberación. Opción por los pobres, ofrece un estudio completo sobre el significado de la opción por los pobres, su desarrollo y distintos matices.
} 
cristiano, y consiguientemente son el lugar privilegiado de la praxis y reflexión cristiana" ${ }^{2}$; es decir, son para él un lugar teológico en el sentido de que son el lugar más apto para la vivencia de la fe de Jesús y para la comprensión de la praxis del seguimiento ${ }^{63}$.

La opción por los pobres en una espiritualidad de raíz latinoamericana tiene como sustrato la pregunta fundamental por la salvación universal del ser humano. En este sentido, la teología latinoamericana ha destacado la historicidad de la salvación cristiana ${ }^{64} \mathrm{y}$, por ende, la necesidad de relacionar la particularidad o la singularidad con la universalidad. Esta reflexión teológica encuentra su comprensión en las categorías de Reinado de Dios y encarnación. El Reino de Dios es inseparable de la persona de Jesús como el Ungido, el Hijo lleno del Espíritu Santo.

Además resalta la relación íntima entre creación, redención y salvación. El Dios creador es el mismo que ha irrumpido en Jesucristo y el Espíritu para nuestra salvación. Creación y redención son vistas en su unidad. En este sentido actuaron como íconos preparatorios en el Antiguo Testamento, tanto el éxodo del pueblo de Israel en que Dios se hace presente en la historia para liberar a su pueblo, como el cautiverio y la acción de los profetas, en quienes habló el Espíritu Santo.

Esta realidad salvífica alcanzó su sentido pleno en Jesucristo, en su predicación y praxis, que tienen como centro el Reinado de Dios: todo como un único movimiento o única historia de salvación en la que, ciertamente, se trata de una liberación integral con fundamento teológico estricto que incluye la dimensión histórica y política. Gutiérrez, tras citar Lumen gentium 16, Gaudium et spes 3 y 22, indica:

La salvación no es algo ultramundano, frente a lo cual la vida presente sería solo una prueba. La salvación-comunión de los hombres con Dios y comunión de los hombres entre sí, es algo que se da también real y concretamente desde ahora. ${ }^{65}$

Y agrega:

...en concreto no hay dos historias, una profana y otra sagrada, yuxtapuestas o estrechamente ligadas, sino un solo devenir humano asumido irreversiblemente por Cristo, Señor de la historia. Su obra redentora abarca todas las dimensiones de la existencia y la conduce a su pleno cumplimiento. ${ }^{66}$

\footnotetext{
${ }^{62}$ Ellacuría, Conversión de la Iglesia al Reino de Dios. Para anunciarlo y realizarlo en la historia, 163.

${ }^{63}$ Ibíd., 166.

${ }^{64}$ Ellacuría, "Historicidad de la salvación cristiana", 323-372; véase también a Casaldáliga y Vigíl, Espiritualidad de la liberación.

${ }^{65}$ Gutiérrez, Teología de la Liberación. Perspectivas, 197; véase también a Assmann, Teología desde la praxis de la liberación.

${ }^{66}$ Ibíd., 199.
} 
En una primera fase de la reflexión, en la que se relacionaron íntimamente los temas de la salvación, Reinado de Dios y conversión, los teólogos latinoamericanos no se preguntaron de manera significativa por la salvación en sí de quienes no son cristianos, ni menos aún, la posibilidad de salvación en las otras religiones ${ }^{67}$. Más bien abordaron el tema de la salvación como liberación del pecado y de sus estructuras. Así lo resumió Sobrino:

En primer lugar, la predicación de la Buena Nueva se hace en el contexto de un mundo de pecado. Esto significa que estructuralmente esa Buena Nueva tiene que ser comprendida no meramente como libertad, sino como liberación. En segundo lugar, Jesús considera el pecado no meramente en su aspecto ético, sino estrictamente teológico, donde hay que notar que el pecado no es solo negación de Dios, sino formalmente la negación del Reino [...] el pecado no solo aparece como algo que debe ser perdonado sino como algo que debe ser quitado. ${ }^{68}$

No obstante -como intenté mostrar en otro trabajo ${ }^{69}-$, esta misma raíz teológico-espiritual llevó, poco a poco, a la apertura de lo diverso, tanto cultural como religiosamente hablando, así como a la acogida de los diversos rostros de los más pobres.

Segundo Galilea llamó la atención sobre las miopías que se pueden dar si se malentiende la opción por los pobres. Principalmente destacó el error que significaría contraponer dos perspectivas: hacer discípulos u optar por los pobres y su liberación. En realidad se trata de una misma misión en la que una perspectiva implica la otra:

Parece claro que el objetivo esencial de la misión no puede ser una categoría sociológica, sino teológica, encarnada en las distintas realidades. Este objetivo consiste en hacer discípulos de Jesús según el texto misionero clásico de Mt 28,19. Así, la esencia del envío es el discipulado [...] Pero al mismo tiempo la predilección por los pobres y el envío a ellos es una condición esencial del anuncio del Reino. ${ }^{70}$

Para Gustavo Gutiérrez, la opción por los pobres quiere evitar la exclusión de quienes eran marginados; también pretende resaltar el aspecto teocéntrico del Reino: es decir, que Dios es quien toma la iniciativa e irrumpe, y que es el rostro de Dios el que se revela y manifiesta un amor gratuito, comprometido y misericordioso, amor

\footnotetext{
${ }^{67}$ Véase a Merino, Teología latinoamericana y pluralismo religioso.

${ }^{68}$ Sobrino, Cristología desde América Latina, 55-56.

${ }^{69}$ Merino, Teología latinoamericana y pluralismo religioso; Merino, "La diversidad religiosa como problema teológico en América Latina. Relación entre la teología de la liberación y la religiosidad popular”. Ambos trabajos profundizan sobre el tema de la acogida de la diversidad en América Latina.
}

${ }^{70}$ Galilea, El Reino de Dios y la liberación del hombre, 157. 
que no se ajusta al pensamiento humano, porque él no hace las cosas al estilo humano y rompe nuestros esquemas.

Para sensibilidades más actuales habría que decir que ubicar a Jesucristo en el centro evitaría cualquier forma de exclusión, de piscología de élite o de una Iglesia que se siente aduana ${ }^{71}$. Debemos entender que solo el Espíritu Santo sabe poner a Jesús y a Dios en el centro. $\mathrm{Al}$ respecto, Gutiérrez nos dice:

El motivo último del compromiso con los pobres y oprimidos no está en el análisis social que empleamos, en nuestra compasión humana o en la experiencia directa que podamos tener de la pobreza. Todas ellas son razones válidas que juegan sin duda un papel importante en nuestro compromiso, pero, en tanto que cristianas, este se basa fundamentalmente en el Dios de nuestra fe. Es una opción teocéntrica y profética que hunde sus raíces en la gratuidad del amor de Dios y es exigida por ella. ${ }^{72}$

\section{A modo de conclusión abierta}

La actuación libre y gratuita de Dios rompe esquemas para liberar y universalizar lo que el hombre ha encasillado, esclavizado, excluido o rechazado; en una palabra, rompe cualquier tipo de idolatría o pretensión de superioridad. En el fondo es la gratuidad amorosa y misericordiosa de Dios -que se manifiesta en la categoría de Reino de Dios en favor de los marginados- la que permite superar cualquier visión estrecha o exclusivista.

La gratuidad de Dios nos abre a la novedad y a la universalidad porque rompe los límites que los hombres han impuesto. Esto evita poner límites a la acción de Dios y absolutizar las opciones humanas. Así, la acción de Dios y su opción por los pobres son la cara concreta del amor gratuito y universal de $\operatorname{Dios}^{73}$, quien desea que todos se salven. Es decir, no sería esta o aquella condición, ya sea social o religiosa, la que determinaría el amor de Dios y su salvación, sino simplemente su amor gratuito, el cual es siempre sorprendente.

La contemplación del misterio de la encarnación y del Reinado de Dios desde la realidad concreta de los pueblos latinoamericanos, permitieron a los principales autores teológicos y animadores pastorales, develar una espiritualidad que iluminó la teología y pastoral latinoamericana, propiciando con ello un discipulado abierto al diálogo y al encuentro del otro, el cual se basó en la comprensión del otro/diverso como próximo. Esta espiritualidad que sale al encuentro del prójimo es coincidente con la propuesta del papa Francisco que

\footnotetext{
${ }^{71}$ Francisco, "Carta del santo padre al pueblo de Dios que peregrina en Chile, 31 de mayo de 2018".

${ }^{72}$ Gutiérrez, "Pobres y opción fundamental”, 309-310.

${ }^{73}$ Ibíd., 310-311.
} 
nos invita a ser discípulos misioneros constructores de una cultura del encuentro. Así mismo, esta espiritualidad de raíz latinoamericana nos aporta un horizonte rico y más amplio, que puede complementar los aportes que, en los estudios hasta ahora publicados, quedan reducidos a la influencia que pueda tener en la propuesta del papa Francisco la teología del pueblo y la espiritualidad jesuita.

\section{Referencias bibliográficas}

Albado, Omar César. "La teología del pueblo: su contexto latinoamericano y su influencia en el papa Francisco". Revista cultura teológica 91 (2018): 31-57.

Assman, Hugo. Teología desde la praxis de la liberación. Salamanca: Sígueme, 1973.

Awi, Alexandre. "El papa Francisco y la cultura del encuentro". Medellín 169 (2017): 721-750.

Azcuy, Virginia. "Evangelización con Espíritu (EG 261). La unidad de la teología, la espiritualidad y la pastoral al servicio del anuncio del Evangelio". Teología 114 (2014): 73-93.

Bingemer, María Clara Luccetti. "La consolación y el bien mayor. Sobre la espiritualidad y la inteligencia de la fe del papa Francisco". Medellín 168 (2017): 532-550.

Boff, Leonardo. La fe en la periferia del mundo. El caminar de la Iglesia con los oprimidos. Santander: Sal Terrae, 1981 [1985].

. Vivir en el Espíritu según el Espíritu. Bogotá: Indo American Press, 1985.

Bresciani, Carlos, y otros. El papa Francisco y la espiritualidad. Santiago de Chile: CEI, 2017.

Brighenti, Agenor. "Criterios para una lectura del Documento de Aparecida. El pretexto, el contexto y el texto". Revista latinoamericana de teología 71 (2007): 161-180. . Para entender Aparecida. Bogotá: San Pablo, 2014.

Casaldáliga, Pedro; y José María Vigil. Espiritualidad de la liberación. Santander: Sal Terrae, 1992.

Congregación para la Doctrina de la Fe. "Instrucción libertatis conscientia sobre libertad cristiana y liberación (1986)". Vatican, https://www.vatican.va/roman curia/ congregations/cfaith/documents/rc con cfaith doc 19860322 freedomliberation_sp.html (consultado el 18 de enero de 2020).

Consejo Episcopal Latinoamericano. Las cinco conferencias generales del episcopado latinoamericano. Bogotá: Celam-San Pablo, 2014. 
Costadoat, Jorge. "Cristo liberador, mediador absoluto del Reino de Dios". Teología y vida 49 (2008): 97-113.

Cozzi, Alberto. "El exceso del origen y la novedad del don. Caminos recientes para decir la acción, la presencia y la identidad del Espíritu de Cristo". Estudios trinitarios 50 (2016): 51-97.

Del Cura, Santiago. "El Dios más humano: la espiritualidad que bebe en las fuentes del Dios Trinitario". Estudios trinitarios 49 (2015): 221-280.

Ellacuría, Ignacio. Conversión de la Iglesia al reino de Dios. Para anunciarlo y realizarlo en la historia. Santander: Sal Terrae, 1984.

. "Historicidad de la salvación cristiana". En Mysterium liberationis I, dirigido por Ignacio Ellacuría y Jon Sobrino, 323-372. Madrid: Trotta, 1990.

Fares, Diego. El olor del pastor. El ministerio pastoral en la visión del papa Francisco. Santander: Sal Terrae, 2015.

Ferrara, Ricardo; y Carlos Galli (eds.). Presente y futuro de la teología en Argentina. Homenaje a Lucio Gera. Buenos Aires: Paulinas, 1997.

Francisco. "Carta del santo padre al pueblo de Dios que peregrina en Chile, 31 de mayo de 2018". Vatican, http://www.vatican.va/content/francesco/es/ letters/2018/documents/papa-francesco 20180531 lettera-popolodidio-cile. html (consultado el 18 de enero de 2020).

- "Exhortación apostólica Evangelii gaudium sobre el anuncio del Evangelio en el mundo actual (2013)". Vatican, https://www.vatican.va/content/francesco/ es/apost exhortations/documents/papa-francesco esortazione-ap 20131124 evangelii-gaudium.html (consultado el 18 de enero de 2020).

- "Vigilia de Pentecostés con los movimientos eclesiales. Palabras del santo padre (18 de mayo de 2013)". Vatican, https://www.vatican.va/content/francesco/es/ speeches/2013/may/documents/papa-francesco 20130518 veglia-pentecoste.

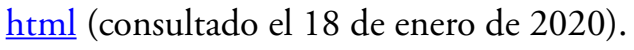

- "Visita a Bari: Palabras del santo padre al término de la jornada (7 de julio de 2018)". Vatican, http://w2.vatican.va/content/francesco/es/events/event.dir. html/content/vaticanevents/es/2018/7/7/visitabari-conclusione.html (consultado el 18 de enero de 2020).

Galilea, Segundo. El camino de la espiritualidad. Bogotá: Paulinas, 1987. . El Reino de Dios y la liberación del hombre. Bogotá: Paulinas, 1988. 
. La inserción en la vida de Jesús y en la misión. Santiago de Chile: Paulinas, 1989.

. "La liberación como encuentro de la política y de la contemplación”. Concilium 96 (1974): 313-327.

- ¿Los pobres nos evangelizan? Bogotá: Indo American Press, 1977.

. Religiosidad popular y pastoral. Madrid: Cristiandad, 1979.

Galli, Carlos. "Francisco y Aparecida hacia el futuro”. Pontificia Comisión para América Latina, http://www.americalatina.va/content/dam/americalatina/Documents/ Francisco $\% 20 \mathrm{y} \% 20$ Aparecida $\% 20$ hacia $\% 20 \mathrm{el} \% 20$ futuro\%20-\%20Galli.pdf (consultado el 10 de junio de 2020).

. "Lectura teológica del texto de Evangelii gaudium en el contexto del ministerio pastoral del papa Francisco”. Medellín 168 (2014): 47-88.

. "Pablo VI y Francisco. La alegría de Cristo". Generación Francisco, http:// generacionfrancisco.org.ar/documentos/Galli\%20-\%20PABLO $\% 20 \mathrm{VI} \% 20$ Y\%20FRANCISCO.pdf (consultado el 3 de febrero de 2020).

Gutiérrez, Gustavo. Beber del propio pozo. Lima: CEP, 1983.

. Hablar de Dios desde el sufrimiento del inocente. Salamanca: Sígueme, 1988.

. "Pobres y opción fundamental". En Mysterium liberationis I, dirigido por Ignacio Ellacuría y Jon Sobrino, 303-322. Madrid: Trotta, 1990.

. "Praxis de liberación. Teología y anuncio". Concilium 96 (1974): 353-374.

. Teología de la liberación. Perspectivas. Salamanca: Sígueme, 1974.

Juan Pablo II. "Carta encíclica Redemptoris misio sobre la permanente validez del mandato misionero (1990)". Vatican, https://www.vatican.va/content/johnpaul-ii/es/encyclicals/documents/hf jp-ii enc 07121990 redemptoris-missio. html (consultado el 10 de junio de 2020).

Lois, Julio. Teología de la liberación. Opción por los pobres. Madrid: Iepala, 1986.

Lucciani, Rafael. El papa Francisco y la teología del pueblo. Madrid: PPC, 2016.

Martínez, Julio. La cultura del encuentro. Desafío e interpelación para Europa. Santander: Sal Terrae, 2017.

Merino, Patricio. "El aporte de Segundo Galilea a la interrelación entre espiritualidad, teología y pastoral. Clave pneumatológica”. Teología 130 (2019): 45-66.

. "Homenaje a una vida y obra: Segundo Galilea, discípulo misionero de Jesucristo". Medellin 135 (2008): 539-557. 
- La categoría teológica signos de los tiempos. Desde el Concilio Vaticano II al Pentecostés de Aparecida y Francisco. Bogotá: USTA, 2014.

- "La diversidad religiosa como problema teológico en América Latina. Relación entre la teología de la liberación y la religiosidad popular". Anales de teología 16/2 (2014): 245-279.

- "La otra economía: el Dios en salida como contenido y fuente de Evangelii gaudium". Medellín 158 (2014): 109-124.

. Teología latinoamericana y pluralismo religioso. Salamanca: UPSA, 2012.

Pablo VI. "Carta encíclica Ecclesiam suam. El 'mandato' de la Iglesia en el mundo moderno (1964)". Vatican, https://www.vatican.va/content/paul-vi/es/encyclicals/documents/hf p-vi enc 06081964 ecclesiam.html (consultado el 10 de junio de 2020).

. "Exhortación apostólica Evangelii nuntiandi al episcopado, al clero y a los fieles de toda la Iglesia acerca de la evangelización en el mundo contemporáneo (1975)". Vatican, https://www.vatican.va/content/paul-vi/es/ apost exhortations/documents/hf p-vi exh 19751208 evangelii-nuntiandi. html (consultado el 10 de junio de 2020).

Scannone, Juan Carlos. "La teología de la liberación. Caracterización, corrientes, etapas". Stromata 48 (1982): 3-40.

. La teología del pueblo. Raices teológicas del papa Francisco. Santander: Sal Terrae, 2017.

. Teología, cultura popular y discernimiento. Salamanca: Sígueme, 1977.

Sobrino, Jon. Cristología desde América Latina. México: Ediciones CRT, 1977.

. "Espiritualidad y liberación”. Selecciones de teología 23/92 (1984): 139-162.

Disponible en: Selecciones de teología, https://seleccionesdeteologia.net/selecciones/llib/vol23/92/092 sobrino.pdf (consultado el 10 de junio de 2020).

. Liberación con Espiritu. Apuntes para una nueva espiritualidad. Santander: Sal Terrae, 1985.

Teixeira, Faustino. "La teología del pluralismo religioso en América Latina”. En Por los muchos caminos de Dios. IV: Teología liberadora intercontinental del pluralismo religioso, organizado por José María Vigíl, María Luiza Tomita y Marcelo Barros. Quito: Abya-Yala, 2006. 
. "La teología de la liberación. Caracterización, corrientes, etapas". Stromata 48 (1982): 3-40.

. La Teología del Pueblo. Raíces teológicas del Papa Francisco. Santander: Sal Terrae, 2017.

Sobrino, Jon. Cristología desde América Latina. México: Ediciones CRT, 1977.

_. Conversión de la Iglesia al Reino de Dios. Para anunciarlo y realizarlo en la historia. Santander: Sal Terrae, 1984.

. "Espiritualidad y liberación”. Sal Terrae 72 (1984): 139-162.

. Liberación con Espiritu. Apuntes para una nueva espiritualidad. Santander: Sal Terrae, 1985.

. Espiritualidad de La liberación. Bogotá: Paulinas, 1992.

Texeira, Faustino. "La teología del pluralismo religioso en América Latina”. En Vigíl, José María; Tomita, María Luiza; Barros, Marcelo y otros. Por los muchos caminos de Dios. IV: Quito: Abya-Yala, 2006. 